\title{
NITROGEN K-SHELL PHOTOABSORPTION
}

\author{
J. García ${ }^{1,2}$, T. R. Kallman ${ }^{2}$, M. Witthoeft ${ }^{2}$, E. Behar ${ }^{2,8}$, C. Mendoza ${ }^{3}$, P. Palmeri ${ }^{4}$, P. Quinet ${ }^{4,5}$, M.A. Bautista ${ }^{6,9}$, \\ AND M. KLAPISCH ${ }^{7}$ \\ ${ }^{1}$ The Catholic University of America, IACS, Physics Department, Washington DC 20064, USA; javier@milkyway.gsfc.nasa.gov \\ 2 NASA Goddard Space Flight Center, Greenbelt, MD 20771, USA; michael.c.witthoeft@ nasa.gov, timothy.r.kallman@nasa.gov, behar@milkyway.gsfc.nasa.gov \\ ${ }^{3}$ Centro de Física, IVIC, Caracas 1020A, Venezuela; claudio@ivic.ve \\ ${ }^{4}$ Astrophysique et Spectroscopie, Université de Mons, B-7000 Mons, Belgium; palmeri@umons.ac.be \\ ${ }^{5}$ IPNAS, Sart Tilman B15, Université de Liège, B-4000 Liège, Belgium; quinet@umons.ac.be \\ ${ }^{6}$ Virginia Polytechnic Institute and State University, Blacksburg, VA 24061, USA; bautista@ vt.edu \\ ${ }^{7}$ ARTEP, Inc., Ellicott City, MD 21042, USA; marcel.klapisch.ctr@nrl.navy.mil \\ Received 2009 September 1; accepted 2009 October 22; published 2009 November 19
}

\begin{abstract}
Reliable atomic data have been computed for the spectral modeling of the nitrogen $\mathrm{K}$ lines, which may lead to useful astrophysical diagnostics. Data sets comprise valence and K-vacancy level energies, wavelengths, Einstein $A$-coefficients, radiative and Auger widths, and K-edge photoionization cross sections. An important issue is the lack of measurements that are usually employed to fine-tune calculations so as to attain spectroscopic accuracy. In order to estimate data quality, several atomic structure codes are used and extensive comparisons with previous theoretical data have been carried out. In the calculation of $\mathrm{K}$ photoabsorption with the Breit-Pauli $R$-matrix method, both radiation and Auger dampings, which cause the smearing of the K edge, are taken into account. This work is part of a wider project to compute atomic data in the X-ray regime to be included in the database of the popular XSTAR modeling code.
\end{abstract}

Key words: atomic data - atomic processes - line: formation - X-rays: general

Online-only material: machine-readable tables

\section{INTRODUCTION}

The improved resolution and sensitivity of current satelliteborne X-ray observatories (Chandra and XMM-Newton) are allowing the study of previously inaccessible weak spectral features of astrophysical interest. In the early stages of these missions, it was realized that absorption by near-neutral species was common, and the fact that all charge states (except the fully ionized) left identifiable imprints in the X-ray spectrum has proven to be a powerful diagnostic. Inner-shell absorption is important in the outflows of Seyfert galaxies in terms of both $\mathrm{Fe}$ $\mathrm{L} \alpha$ (Sako et al. 2001; Behar et al. 2001) and $\mathrm{K} \alpha$ lines of high- $Z$ elements (Behar \& Netzer 2002), and also of elements in the first row of the periodic table such as oxygen (Pradhan 2000; Behar et al. 2003; García et al. 2005). Furthermore, inner-shell absorption of continuum X-rays from bright galactic sources is a useful diagnostic of the interstellar medium (Yao et al. 2009; Kaastra et al. 2009).

Nitrogen K-shell absorption and emission are detected in $\mathrm{X}$-ray spectra, mostly due to the $\mathrm{H}$ - and He-like charge states. For instance, observations of the emission lines of N VI and $\mathrm{N}$ VII in the ejecta of $\eta$ Carinae by Leutenegger et al. (2003) have resulted in the lower bound N/O > 9 for its nitrogen abundance. This result puts a constraint on the evolution of $\eta$ $\mathrm{Car}$ and is a signature of $\mathrm{CNO}$-cycle processing. The $\mathrm{N}$ vi triplet is observed in the spectrum of the magnetic B star $\beta$ Cep where it has been used to test magnetically confined wind shock models (Favata et al. 2009). It is found that the plasma is not heated by magnetic reconnection and there is no evidence for an optically

\footnotetext{
8 Visiting senior NPP fellow. Permanent address: Department of Physics, Technion, Haifa 32000, Israel.

9 Current address: Department of Physics, Western Michigan University, Kalamazoo, MI 49008, USA.
}

thick disk at the magnetic equator. Highly ionized emission lines of nitrogen have been observed by Miyata et al. (2008) on the north-eastern rim of the Cygnus Loop supernova remnant, which can be used to determine nitrogen abundances, which turn out to be 23\% solar. Seyfert galaxy outflows also can have super-solar $\mathrm{N}$ abundances (Brinkman et al. 2002; Arav et al. 2007).

Narrow absorption $\mathrm{K} \alpha$ and $\mathrm{K} \beta$ lines of $\mathrm{N} v \mathrm{v}$ have been identified in the warm absorber of the MR 2251-178 quasar, which point to a complex velocity field with an outflow of ionized material (Ramírez et al. 2008). K-shell absorption by Li-like $\mathrm{N} \mathrm{v}$, which has prominent UV lines, or by lower charge states at wavelengths $\lambda>29 \AA$ is difficult to detect due to the reduced sensitivity of current X-ray instruments toward these longer wavelengths. Notable exceptions include: $\mathrm{K} \alpha$ absorption by N v at $29.42 \AA$ has been reported by Steenbrugge et al. (2005) in the outflow of NGC 5548; and N absorption by a white dwarf outflow has been observed following the outburst of nova V4743 Sagittarii (Ness et al. 2003). In the latter case, only the H- and $\mathrm{He}$-lines are discussed, but lower charge states of $\mathrm{N}$ are clearly seen in the spectrum longward of $29 \AA$ (see Figure 3(b) in Ness et al. 2003).

The current proliferation of X-ray spectra with high signalto-noise ratio in astronomical archives makes the computation of nitrogen K-shell photoabsorption particularly timely. This is also an additional and important step in the ongoing effort to compute reliable atomic data by García et al. (2005), Palmeri et al. (2008a), Palmeri et al. (2008b), and Witthoeft et al. (2009) for K-line analysis within the context of the xsTAR spectral modeling code (Kallman \& Bautista 2001). Available spectroscopic data for K-vacancy levels of the $\mathrm{N}$ isonuclear sequence are notably scarce, mainly limited to $\mathrm{N} \mathrm{v}$ and $\mathrm{N}$ VI for which a few levels are listed in the NIST database (Ralchenko et al. 2008) and four measured wavelengths have 
been reported by Beiersdorfer et al. (1999). This shortage of reliable measurements precludes empirical corrections to calculated level energies. On the other hand, several relativistic methods have been previously used to generate atomic data for nitrogen K-vacancy states: the saddle-point complex-rotation method (Davis \& Chung 1989; Chung 1990; Shiu et al. 2001; Lin et al. 2001, 2002; Zhang et al. 2005); the Raleigh-Ritz variational method (Hsu et al. 1991; Yang \& Chung 1995; Wang \& Gou 2006); and multiconfiguration Dirac-Fock (MCDF) approaches such as those by Hata \& Grant (1983); Hardis et al. (1984); Chen (1986); Chen \& Crasemann (1987, 1988); and Chen et al. (1997). Photoabsorption cross sections in the near K-edge region of $\mathrm{N}$ ions have been obtained by Hartree-Slater centralfield computations (Reilman \& Manson 1979), where the resonance structure due to quasibound states as well as configuration correlations are neglected. The net effect of the resonance structure is to fill in the photoionization cross section below the inner-shell threshold altering the shape of the $\mathrm{K}$ edge.

In this paper, we report on calculations of energy level structure and bound-bound and bound-free transition probabilities for the $\mathrm{K}$ shell of nitrogen. The outline of the present report is as follows. The numerical methods are briefly described in Section 2 while an analysis of the results based on comparisons with previous experimental and theoretical values is carried out in Sections 3-8. The two supplementary electronic tables are explained in Section 9 while some conclusions are finally discussed in Section 10.

\section{NUMERICAL METHODS}

The numerical approach used here has been fully described in Bautista et al. (2003). Level energies, wavelengths, Acoefficients, and radiative and Auger rates are computed with the codes AUtostructure (Eissner et al. 1974; Badnell 1986, 1997) and HFR (Cowan 1981). For consistency, configurationinteraction $(\mathrm{CI})$ wave functions of the type

$$
\Psi=\sum c_{i} \phi_{i}
$$

are calculated with the relativistic Breit-Pauli Hamiltonian

$$
H_{\mathrm{bp}}=H_{\mathrm{nr}}+H_{1 \mathrm{~b}}+H_{2 \mathrm{~b}}
$$

where $H_{\mathrm{nr}}$ is the usual non-relativistic Hamiltonian. The onebody relativistic operators

$$
H_{1 \mathrm{~b}}=\sum_{n=1}^{N} f_{n}(\text { mass })+f_{n}(\mathrm{~d})+f_{n}(\mathrm{so})
$$

represent the spin-orbit interaction, $f_{n}$ (so), the non-finestructure mass variation, $f_{n}$ (mass), and the one-body Darwin correction, $f_{n}(\mathrm{~d})$. The two-body Breit operators are given by

$H_{2 \mathrm{~b}}=\sum_{n<m} g_{n m}(\mathrm{so})+g_{n m}(\mathrm{ss})+g_{n m}(\mathrm{css})+g_{n m}(\mathrm{~d})+g_{n m}(\mathrm{oo})$,

where the fine-structure terms are $g_{n m}$ (so) (spin-other-orbit and mutual spin-orbit); $g_{n m}$ (ss) (spin-spin); and the nonfine-structure counterparts $g_{n m}(\mathrm{css})$ (spin-spin contact), $g_{n m}(d)$ (two-body Darwin), and $g_{n m}(\mathrm{oo})$ (orbit-orbit). It must be pointed out that HFR neglects contributions from the two-body term $\mathrm{H}_{2 \mathrm{~b}}$ of Equation (4).

In HFR, core-relaxation effects (CRE) are always taken into account since each electron configuration is represented with its own set of non-orthogonal orbitals optimized by minimizing the average configuration energy. In AUTOSTRUCTURE, on the other hand, configurations may be represented with either orthogonal or non-orthogonal orbitals, which then enables estimates of the importance of these effects. In the present calculation, five approximations are considered in order to study the effects of electron correlation, i.e., configuration interaction (CI) and CRE, and thus to estimate data accuracy.

Approximation AS1 Atomic data are computed with AUTOSTRUCTURE including CI from only the $n=2$ complex. CRE are neglected.

Approximation AS2 Atomic data are computed with AUTOSTRUCTURE including both $n=2 \mathrm{CI}$ and CRE.

Approximation AS3 Atomic data are computed with AUTOSTRUCTURE including CI from both the $n=2$ and $n=3$ complexes. CRE are neglected.

Approximation HF1 Atomic data are computed with HFR including CI only from the $n=2$ complex.

Approximation HF2 Atomic data are computed with HFR including CI from both the $n=2$ and $n=3$ complexes.

Photoabsorption cross sections are obtained with the codes Breit-Pauli R-Matrix (BPRM; Berrington et al. 1987; Seaton 1987) and Hebrew University Lawrence Livermore Atomic Code (Hullac; Bar-Shalom et al. 2001). In BPRM, wave functions for states of an $\mathrm{N}$-electron target and a colliding electron with total angular momentum and parity $J \pi$ are expanded in terms of the target eigenfunctions

$$
\Psi^{J \pi}=\mathcal{A} \sum_{i} \chi_{i} \frac{F_{i}(r)}{r}+\sum_{j} c_{j} \Phi_{j} .
$$

The $\chi_{i}$ functions are vector coupled products of the target eigenfunctions and the angular components of the incident-electron functions; $F_{i}(r)$ are the radial part of the continuum wave functions that describe the motion of the scattered electron; and $\mathcal{A}$ is an antisymmetrization operator. The functions $\Phi_{j}$ are boundtype functions of the total system constructed with target orbitals. The Breit-Pauli relativistic version has been developed by Scott \& Burke (1980) and Scott \& Taylor (1982), but the inclusion of the two-body terms (see Equation (4)) is currently in progress and thus not included. Auger and radiative dampings are taken into account by means of an optical potential (Robicheaux et al. 1995; Gorczyca \& Badnell 1996; Gorczyca $\&$ McLaughlin 2000) where the resonance energy with respect to the threshold acquires an imaginary component. In the present work, the $N$-electron targets are represented with all the fine structure levels within the $n=2$ complex. It is important to mention that the BPRM approach does not allow the inclusion of CRE in the photoionization calculations; therefore, both the initial and final states correspond to configurations represented with orthogonal orbitals. Thus, the wave functions for the target states are those produced with approximation AS1.

HULLAC (Bar-Shalom et al. 2001) is a multiconfiguration computing package based on the relativistic version of the parametric potential method by Klapisch et al. (1977), and employs a factorization-interpolation method within the framework of the distorted wave approximation (Bar-Shalom et al. 1988). It includes the Breit interaction for relativistic configuration averages and can take into account part of the correlation effects by allowing different potentials for each group of configurations. Its newest version (Klapisch \& Busquet 2009), which is 


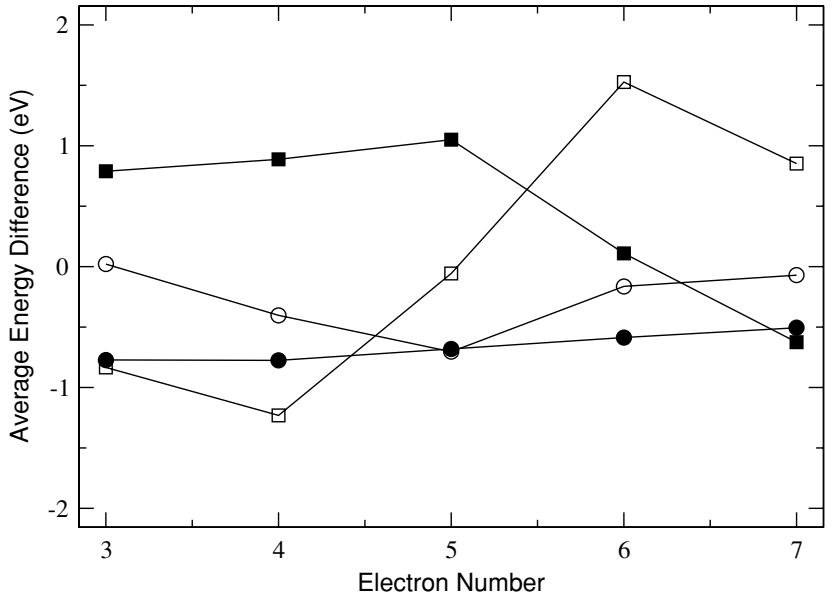

Figure 1. Average level energy differences with respect to approximation AS1 for ions of the nitrogen isonuclear sequence with electron number $3 \leqslant N \leqslant 7$. Filled circles: valence level energies computed with AS2. Open circles: valence level energies computed with AS3. Filled squares: K-vacancy level energies computed with AS2. Open squares: K-vacancy level energies computed with AS3.

used here, incorporates a number of improvements such as important corrections to the photoionization subroutines. For the present work, we calculated only transition energies and direct photoionization cross sections, but HULLAC can also efficiently compute photo-autoionization resonances by means of the isolated resonance approximation (Oreg et al. 1991), which are subsequently superimposed on the continuum photoionization cross section. Moreover, attempts have been made to adapt HULLAC to calculate the quantum interference of resonances with the continuum that leads to Fano-type asymmetric profiles (Behar et al. 2000, 2004). However, these calculations with HULLAC are beyond the scope of the present paper.

\section{ENERGY LEVELS}

Energies have been computed for both valence and K-vacancy levels in the five approximations delineated in Section 2 and with HULLAC. A comparison of approximations AS1 with AS2 provides an estimate of CRE, while those of AS1 with AS3 and HF1 with HF2 give measures of out-of-complex CI. Also, level energy accuracy can be bound with a comparison of AS2 with $\mathrm{HF} 1$, that is, from two physically comparable approximations but calculated with two independent numerical codes.

In Figure 1, average energy differences for AS1 versus AS2 and AS1 versus AS3 are plotted for each ionic species, $3 \leqslant N \leqslant 7$. It may be seen that while CRE lower the valencelevel energies by around $0.5-0.8 \mathrm{eV}$, it raises by a similar amount those for the K-vacancy levels in species with electron number $3 \leqslant N \leqslant 5$; as a consequence, transition wavelengths for these ions are expected to be shorter due to this effect. Although $n=3 \mathrm{CI}$ also causes a lowering (less than $0.7 \mathrm{eV}$ ) of the valence level energies (see Figure 1), the impact on the Kvacancy level energies is more pronounced (as large as $1.5 \mathrm{eV}$ ): it mainly lowers levels for species with $N<5$ and raises those for $N>5$. The latter result is mostly due to $\mathrm{K}$-vacancy levels from the $n=2$ and $n=3$ complexes intermixing in the lowly ionized members.

Figure 2 shows the corresponding quantities for HF1 and HF2. As shown in Figure 2, the effect of CI on the energies computed with HFR is somewhat different as they are decreased (less than $0.5 \mathrm{eV}$ ) for both valence and K-vacancy levels, the minimum occurring in ions with $N=5$ and $N=6$. Level

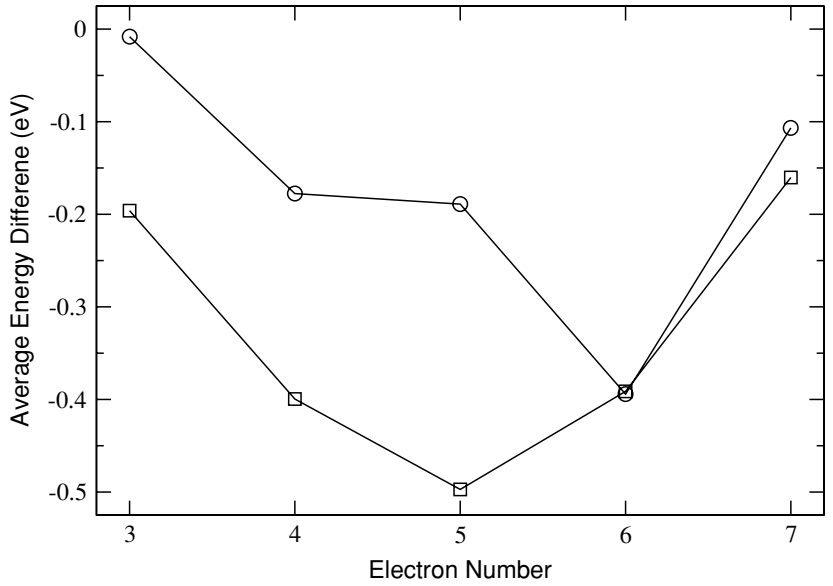

Figure 2. Average level energy differences with respect to approximation HF1 for ions of the nitrogen isonuclear sequence with electron number $3 \leqslant N \leqslant 7$. Open circles: valence level energies computed with HF2. Open squares: Kvacancy level energies computed with HF2.

energy differences between the AS2 and HF1 data sets are within $0.5 \mathrm{eV}$, which is a reliable accuracy ranking of the present level energies.

Computed level energies are compared with the few spectroscopic measurements available $(2 \leqslant N \leqslant 3)$ in Table 1. It may be seen that CRE in AUTOSTRUCTURE (approximation AS2) in general reduce differences with experiment. Furthermore, HFR and HULLAC seem to provide better energies than AUTOSTRUCTURE; differences of HFR (HULLAC) with experiment not being larger than $1.53 \mathrm{eV}(1.19 \mathrm{eV})$. In the He-like system, HULLAC is particularly accurate for triplet states and less so for singlet states. The accurate HF2 approximation is compared with previously computed term energies in Table 2. Although we would not quote present term energies with the same number of significant figures as previous results, HF2 values are consistently lower.

Fine-structure level splittings in HF2 can be problematic as shown in Table 3. It may be seen that HF2 gives a value in good accord $(1 \%)$ with beam-foil measurements for the $\Delta E\left({ }^{5} \mathrm{P}_{2},{ }^{5} \mathrm{P}_{1}\right)$ splitting of the $1 \mathrm{~s} 2 \mathrm{~s} 2 \mathrm{p}^{2}{ }^{5} \mathrm{P} \mathrm{K}$-vacancy term of $\mathrm{N}$ IV but an intolerably discrepant one (factor of 2) for $\Delta E\left({ }^{5} \mathrm{P}_{3},{ }^{5} \mathrm{P}_{2}\right)$. On the other hand, both AS2 splittings are in reasonable agreement (10\%) with experiment and with results obtained with the relativistic Raleigh-Ritz variational method (Yang \& Chung 1995; Wang \& Gou 2006) and MCDF (Hata \& Grant 1983; Hardis et al. 1984). This problem has been shown by Hata \& Grant (1983) to be due to the neglect of the Breit interaction, which is the case in HF2.

The most stringent accuracy requirements for the energies come from the capabilities of the astronomical instruments that can observe these transitions. Current instruments, the Chandra and XMM-Newton gratings, have a resolving power which is nominally $\varepsilon / \Delta \varepsilon \leqslant 1000$, which imposes a resolution of $0.4-0.5 \mathrm{eV}$ in the energy region of the nitrogen $\mathrm{K}$ lines $(400-500 \mathrm{eV})$, essentially the same accuracy we have achieved in the present calculations. However, in spectra with good statistical signal to noise it is possible to determine line centroids to a factor $\sim 3$ more accurately than this. Future instruments, principally the grating instruments considered for the International X-ray Observatory, may also have resolving power as high as 3000 . Knowledge of transition wavelengths and energy levels with this precision is needed for truly unambiguous identification of observed features and comparison with 
Table 1

Measured and Computed $K$-Vacancy Level Energies (eV)

\begin{tabular}{lcccccccc}
\hline \hline$N$ & Level & $E$ & \multicolumn{5}{c}{$E(\mathrm{Th})-E($ Expt $)$} \\
\cline { 3 - 8 } & & Expt & AS1 & AS2 & AS3 & HF1 & HF2 & HULLAC \\
\hline 2 & $1 \mathrm{~s} 2 \mathrm{~s}^{3} \mathrm{~S}_{1}$ & 419.80 & -1.76 & -1.34 & -2.35 & -0.59 & 0.01 \\
2 & $1 \mathrm{~s} 2 \mathrm{p}{ }^{3} \mathrm{P}_{0}^{\mathrm{o}}$ & 426.30 & -1.85 & -0.93 & -2.36 & -0.56 & 0.09 \\
2 & $1 \mathrm{~s} 2 \mathrm{p}{ }^{3} \mathrm{P}_{1}^{\mathrm{O}}$ & 426.30 & -1.85 & -0.93 & -2.36 & -0.54 & 0.11 \\
2 & $1 \mathrm{~s} 2 \mathrm{p}{ }^{3} \mathrm{P}_{2}^{\mathrm{o}}$ & 426.33 & -1.86 & -0.94 & -2.37 & -0.53 & 0.13 \\
2 & $1 \mathrm{~s} 2 \mathrm{~s}{ }^{1} \mathrm{~S}_{0}$ & 426.42 & -1.61 & -0.21 & -2.15 & 0.03 & 0.69 \\
2 & $1 \mathrm{~s} 2 \mathrm{p}{ }^{1} \mathrm{P}_{1}^{\mathrm{o}}$ & 430.70 & -1.64 & -0.85 & -2.24 & -0.24 & & 0.67 \\
3 & $1 \mathrm{~s}\left({ }^{2} \mathrm{~S}\right) 2 \mathrm{~s} 2 \mathrm{p}\left({ }^{3} \mathrm{P}^{\mathrm{o}}\right){ }^{4} \mathrm{P}_{5 / 2}^{\mathrm{o}}$ & 414.61 & -2.49 & -1.97 & -3.64 & -1.48 & -1.53 & 0.42 \\
3 & $1 \mathrm{~s}\left({ }^{2} \mathrm{~S}\right) 2 \mathrm{~s} 2 \mathrm{p}\left({ }^{3} \mathrm{P}^{\mathrm{o}}\right){ }^{2} \mathrm{P}_{3 / 2}^{\mathrm{o}}$ & $421.52^{\mathrm{a}}$ & -1.72 & -0.80 & -2.18 & -0.51 & -0.62 & 0.83 \\
3 & $1 \mathrm{~s}\left({ }^{2} \mathrm{~S}\right) 2 \mathrm{p}^{2}\left({ }^{3} \mathrm{P}\right){ }^{4} \mathrm{P}_{5 / 2}$ & 425.70 & -2.54 & -1.64 & -3.37 & -1.31 & -1.33 & 1.19 \\
\hline
\end{tabular}

Notes. Experimental level energies (relative to the ion ground state) from the NIST database (Ralchenko et al. 2008).

${ }^{a}$ Derived from the wavelength measurement of Beiersdorfer et al. (1999).

Table 2

Computed Total Energies (au) for K-Vacancy Terms

\begin{tabular}{lccc}
\hline \hline$N$ & Term & HF2 & Other Theory \\
\hline 3 & $1 \mathrm{~s} 2 \mathrm{~s} 2 \mathrm{p}^{4} \mathrm{P}^{\mathrm{o}}$ & -33.240 & $-33.192008^{\mathrm{a}},-33.192204^{\mathrm{b}}$ \\
3 & $1 \mathrm{~s}\left({ }^{2} \mathrm{~S}\right) 2 \mathrm{~s} 2 \mathrm{p}\left({ }^{3} \mathrm{P}^{\mathrm{o}}\right){ }^{2} \mathrm{P}^{\mathrm{o}}$ & -32.952 & $-32.919222^{\mathrm{a}}$ \\
3 & $\left.1 \mathrm{~s}\left({ }^{2} \mathrm{~S}\right) 2 \mathrm{~s} 2 \mathrm{p}^{1}{ }^{1} \mathrm{P}^{\mathrm{o}}\right){ }^{2} \mathrm{P}^{\mathrm{o}}$ & -32.777 & $-32.768550^{\mathrm{a}}$ \\
4 & $1 \mathrm{~s} 2 \mathrm{~s}^{2} 2 \mathrm{p}^{3} \mathrm{P}^{\mathrm{o}}$ & -36.219 & $-36.171232^{\mathrm{c}},-36.173064^{\mathrm{d}}$ \\
4 & $1 \mathrm{~s} 2 \mathrm{~s} 2 \mathrm{p}^{2}{ }^{3} \mathrm{~S}$ & -35.646 & $-35.615357^{\mathrm{d}}$ \\
4 & $1 \mathrm{~s} 2 \mathrm{~s} 2 \mathrm{p}^{2}{ }^{3} \mathrm{P}$ & -35.842 & $-35.788866^{\mathrm{d}}$ \\
4 & $1 \mathrm{~s} 2 \mathrm{~s} 2 \mathrm{p}^{2}{ }^{3} \mathrm{P}$ & -35.542 & $-35.536868^{\mathrm{d}}$ \\
4 & $1 \mathrm{~s} 2 \mathrm{~s} 2 \mathrm{p}^{2}{ }^{3} \mathrm{D}$ & -35.815 & $-35.785042^{\mathrm{d}}$ \\
4 & $1 \mathrm{~s} 2 \mathrm{~s}^{2} 2 \mathrm{p}^{1} \mathrm{P}^{\mathrm{o}}$ & -36.081 & $-36.036967^{\mathrm{e}}$ \\
4 & $1 \mathrm{~s} 2 \mathrm{p}^{3}{ }^{1} \mathrm{P}^{\mathrm{o}}$ & -35.086 & $-35.082958^{\mathrm{e}}$ \\
4 & $1 \mathrm{~s} 2 \mathrm{~s} 2 \mathrm{p}^{2}{ }^{1} \mathrm{D}$ & -35.594 & $-35.583448^{\mathrm{f}}$ \\
4 & $1 \mathrm{~s} 2 \mathrm{~s} 2 \mathrm{p}^{2}{ }^{1} \mathrm{P}$ & -35.445 & $-35.435017^{\mathrm{f}}$ \\
4 & $1 \mathrm{~s} 2 \mathrm{~s} 2 \mathrm{p}^{2}{ }^{1} \mathrm{~S}$ & -35.425 & $-35.415017^{\mathrm{f}}$ \\
4 & $1 \mathrm{~s} 2 \mathrm{~s} 2 \mathrm{p}^{2}{ }^{5} \mathrm{P}$ & -36.160 & $-36.0934586^{\mathrm{g}},-36.0934407^{\mathrm{h}}$ \\
4 & $1 \mathrm{~s} 2 \mathrm{p}^{3}{ }^{5} \mathrm{~S}^{\mathrm{o}}$ & -35.596 & $-35.5414665^{\mathrm{g}},-35.5413248^{\mathrm{h}}$ \\
4 & $1 \mathrm{~s} 2 \mathrm{p}^{3}{ }^{3} \mathrm{P}^{\mathrm{o}}$ & -35.214 & $-35.204065^{\mathrm{i}}$ \\
4 & $1 \mathrm{~s} 2 \mathrm{p}^{3}{ }^{3} \mathrm{D}^{\mathrm{o}}$ & -35.387 & $-35.366601^{\mathrm{i}}$ \\
\hline
\end{tabular}

Notes.

${ }^{a}$ Breit-Pauli saddle-point complex-rotation method (Davis \& Chung 1989).

${ }^{\mathrm{b}}$ Relativistic Raleigh-Ritz variational method (Hsu et al. 1991).

${ }^{c}$ Breit-Pauli saddle-point complex-rotation method (Chung 1990).

${ }^{\mathrm{d}}$ Breit-Pauli saddle-point complex-rotation method (Lin et al. 2001).

${ }^{\mathrm{e}}$ Breit-Pauli saddle-point complex-rotation method (Lin et al. 2002).

${ }^{\mathrm{f}}$ Breit-Pauli saddle-point complex-rotation method (Shiu et al. 2001).

g Relativistic Raleigh-Ritz variational method (Wang \& Gou 2006).

${ }^{\text {h }}$ Relativistic Raleigh-Ritz variational method (Yang \& Chung 1995).

${ }^{\text {i }}$ Breit-Pauli saddle-point complex-rotation method (Zhang et al. 2005).

models. Clearly, precise laboratory measurements are irreplaceable requisites in the theoretical fine tuning of these calculations in order to reduce the current uncertainties.

\section{WAVELENGTHS}

The accuracy of computed wavelengths must be determined without a comparison with measurements due to the scarcity of the latter. CRE and $n=3 \mathrm{CI}$ in AUTOSTRUCTURE impact wavelengths in an opposite manner to that displayed for the $\mathrm{K}$-vacancy levels in Figure 1. Specifically, core relaxation on average shortens wavelengths by as much as $150 \mathrm{~m} \AA$ in ions with $2 \leqslant N \leqslant 5$ while the effect is less pronounced on the higher members. CI increases wavelengths by $\sim 50 \mathrm{~m} \AA$ for $N \leqslant 4$ and decreases them by as much as $150 \mathrm{~m} \AA$ for $N \geqslant 5$. CI in HFR in general increases wavelengths with a maximum of $25 \mathrm{~m} \AA$ at $N=5$.
Table 3

Level Splittings $\left(\mathrm{cm}^{-1}\right)$ for the $1 \mathrm{~s} 2 \mathrm{~s} 2 \mathrm{p}^{2}{ }^{5} \mathrm{P}$ K-Vacancy Term of N IV

\begin{tabular}{lcccc}
\hline \hline Level Splitting & Expt $^{\mathrm{a}}$ & HF2 & AS2 & Other Theory \\
\hline$\Delta E\left({ }^{5} \mathrm{P}_{2},{ }^{5} \mathrm{P}_{1}\right)$ & $127 \pm 1$ & 126 & 119 & $127.07^{\mathrm{b}}, 126.9^{\mathrm{c}}, 129.19^{\mathrm{d}}, 128.94^{\mathrm{e}}$ \\
$\Delta E\left({ }^{5} \mathrm{P}_{3},{ }^{5} \mathrm{P}_{2}\right)$ & $79.5 \pm 0.8$ & 188 & 70 & $78.49^{\mathrm{b}}, 78.45^{\mathrm{c}}, 86.72^{\mathrm{d}}, 86.58^{\mathrm{e}}$
\end{tabular}

Notes.

${ }^{\text {a }}$ Beam-foil measurements by Berry et al. (1982).

${ }^{\mathrm{b}}$ Relativistic Raleigh-Ritz variational method (Wang \& Gou 2006).

${ }^{c}$ Relativistic Raleigh-Ritz variational method (Yang \& Chung 1995).

${ }^{\mathrm{d}}$ MCDF-EAL calculation of Hata \& Grant (1983).

${ }^{\mathrm{e}} \mathrm{MCDF}$ calculation of Hardis et al. (1984).

Wavelengths computed with AS2 are on average $7 \pm 21 \mathrm{~m} \AA$ greater than HF1. This finding can be further appreciated in a comparison with the few available measured wavelengths (see Table 4) where computed values are always greater. HF1 differences with experiment are the smallest (less than $37 \mathrm{~mA}$ ) while CRE in AUTOSTRUCTURE (AS2) also reduce discrepancies.

Wavelengths for $\mathrm{K}$ transitions in nitrogen ions have been previously computed with the MCDF method by Chen (1986), Chen \& Crasemann (1987), Chen \& Crasemann (1988), and Chen et al. (1997). While reasonable agreement is found with HF2 for species with $N=3$ (average difference of $13 \pm 25 \mathrm{~m} \AA$ ) and $N=5$ (average difference of $-4 \pm 33 \mathrm{~mA}$ ), puzzling discrepancies are found for those with $N=4$ and $N=6$. As shown in Figure 3, the MCDF wavelengths of Chen \& Crasemann (1987) show the large average difference with respect to HF2 of $155 \pm 45 \mathrm{~m} \AA$; i.e., on average, they are significantly longer. The inconsistent situation in the C-like ion is somewhat different (see Figure 4) where the average difference with HF2 is now $-45 \pm 449 \mathrm{~m} \AA$ showing a very wide and clustered scatter with questionable deviations as large as $800 \mathrm{~m} \AA$. These comparisons lead us to conclude that the wavelengths computed with $\mathrm{HF} 2$, our best approximation, are accurate to better than $100 \mathrm{~m} \AA$.

\section{A-COEFFICIENTS}

By comparing $A$-coefficients computed with approximations AS1 and AS2, CRE on the $\mathrm{K}$ radiative decay process may be estimated. Discarding transitions subject to cancellation which always display large differences, it is found that, for $\log A \geqslant 10$, CRE generally cause differences not greater 
Table 4

Experimental and Theoretical Wavelengths $(\AA)$ for Nitrogen Ions

\begin{tabular}{lccccccrr}
\hline \hline$N$ & Lower Level & Upper Level & $\lambda\left(\right.$ Expt $\left.^{\mathrm{a}}\right)$ & \multicolumn{4}{c}{$\lambda(\mathrm{Th})-\lambda($ Expt $)$} \\
\cline { 5 - 8 } & & & HF1 & AS1 & AS2 & AS3 & HULLAC \\
\hline 2 & $1 \mathrm{~s}^{2}{ }^{1} \mathrm{~S}_{0}$ & $1 \mathrm{~s} 2 \mathrm{~s}^{3} \mathrm{~S}_{1}$ & $29.5321(26)$ & & 0.1266 & 0.0971 & 0.1683 & 0.0012 \\
2 & $1 \mathrm{~s}^{2}{ }^{1} \mathrm{~S}_{0}$ & $1 \mathrm{~s} 2 \mathrm{p}^{3} \mathrm{P}_{1}^{\mathrm{o}}$ & $29.0835(26)$ & 0.0374 & 0.1274 & 0.0642 & 0.1627 & -0.0074 \\
2 & $1 \mathrm{~s}^{1} \mathrm{~S}_{0}$ & $1 \mathrm{~s} 2 \mathrm{p}{ }^{1} \mathrm{P}_{1}^{\mathrm{o}}$ & $28.7861(22)$ & 0.0167 & 0.1108 & 0.0576 & 0.1515 & -0.0444 \\
3 & $1 \mathrm{~s}^{2} 2 \mathrm{~s}^{2} \mathrm{~S}_{1 / 2}$ & $1 \mathrm{~s} 2 \mathrm{~s} 2 \mathrm{p}^{2} \mathrm{P}_{3 / 2}^{\mathrm{o}}$ & $29.4135(37)$ & 0.0353 & 0.1208 & 0.0560 & 0.1550 & -0.0573 \\
\hline
\end{tabular}

Note.

${ }^{\text {a }}$ Wavelength measurements by Beiersdorfer et al. (1999).

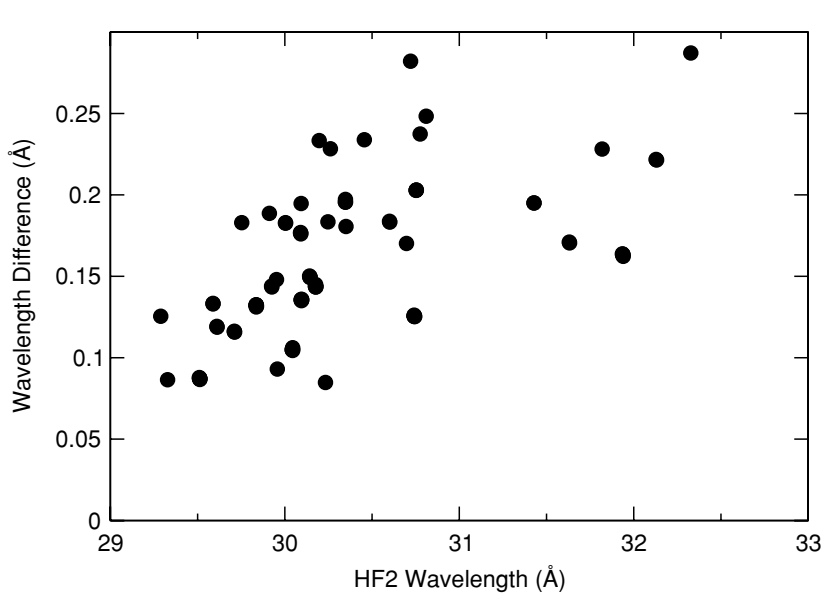

Figure 3. Wavelength differences between MCDF (Chen \& Crasemann 1987) and HF2 for N IV. An average difference of $155 \pm 45 \mathrm{~m} \AA$ is observed.

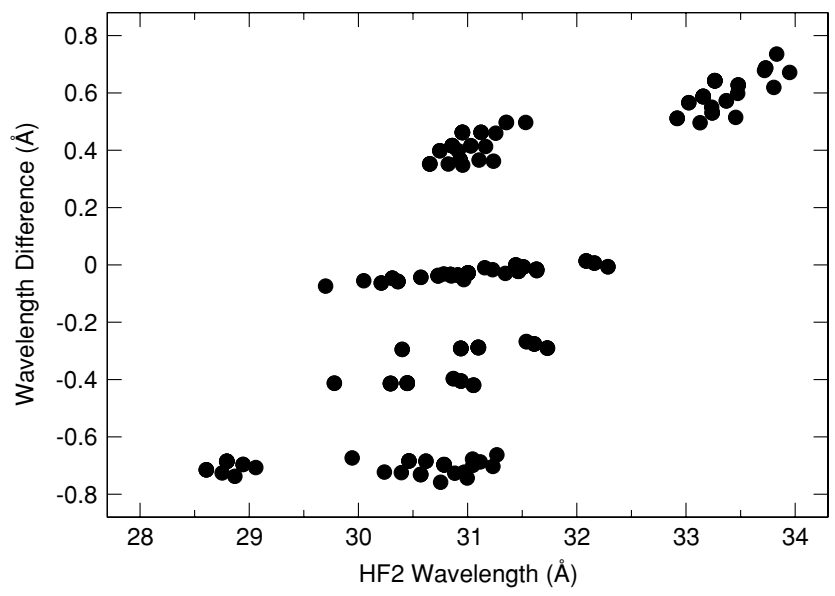

Figure 4. Wavelength differences between MCDF (Chen et al. 1997) and HF2 for N II. Differences as large as $800 \mathrm{~m} \AA$ are observed.

than $20 \%$. However, larger discrepancies (54\%) are found for transitions undergoing multiple electron jumps such as those tabulated in Table 5. A-coefficients for these peculiar transitions computed with HF1, which should be comparable to AS2, are also included in Table 5 finding good agreement (within $15 \%$ ); in fact, differences between $A$-coefficients computed with approximations AS2 and HF1 are in general within $22 \%$. Furthermore, CI from the $n=3$ complex tends to decrease $A$ coefficients with $\log A \geqslant 10$, AS3 being on average $16 \%$ lower than AS1 and HF2 6\% lower than HF1.

MCDF A-coefficients by Chen (1986), Chen \& Crasemann (1987), Chen \& Crasemann (1988), and Chen et al. (1997) agree with HF2 to around $25 \%$ except for $N=6$ where they are found to be, on average, higher by a factor of 4 (see Figure 5). This outcome certainly questions the accuracy of the MCDF

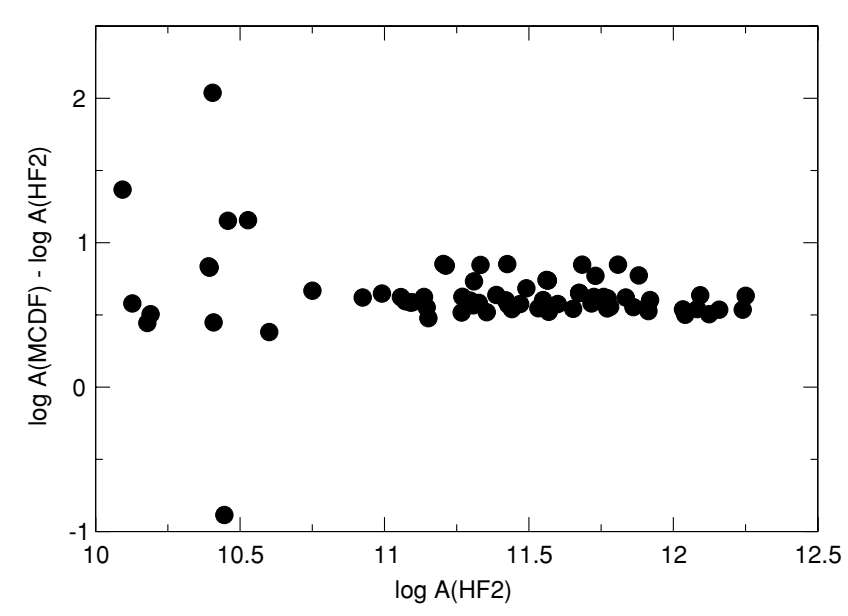

Figure 5. $A$-coefficient differences $\left(\mathrm{s}^{-1}\right)$ between MCDF (Chen et al. 1997) and $\mathrm{HF} 2$ for $\mathrm{N}$ II. It is found that MCDF is on average higher by a factor of 4 .

Table 5

Core-relaxation Effects on K Radiative Decay

\begin{tabular}{lccccc}
\hline \hline$N$ & $j$ & $i$ & \multicolumn{3}{c}{$A_{j i}\left(\mathrm{~s}^{-1}\right)$} \\
\cline { 3 - 6 } & & & $\mathrm{AS} 1$ & $\mathrm{AS} 2$ & $\mathrm{HF} 1$ \\
\hline 3 & $1 \mathrm{~s} 2 \mathrm{~s}^{2}{ }^{2} \mathrm{~S}_{1 / 2}$ & $1 \mathrm{~s}^{2} 2 \mathrm{p}^{2} \mathrm{P}_{1 / 2}^{\mathrm{o}}$ & $3.85 \mathrm{E}+10$ & $5.36 \mathrm{E}+10$ & $4.63 \mathrm{E}+10$ \\
3 & $1 \mathrm{~s} 2 \mathrm{~s}^{2}{ }^{2} \mathrm{~S}_{1 / 2}$ & $1 \mathrm{~s}^{2} 2 \mathrm{p}^{2} \mathrm{P}_{3 / 2}^{\mathrm{o}}$ & $7.62 \mathrm{E}+10$ & $1.06 \mathrm{E}+11$ & $9.18 \mathrm{E}+10$ \\
4 & $1 \mathrm{~s} 2 \mathrm{~s}^{2} 2 \mathrm{p}{ }^{1} \mathrm{P}_{1}^{\mathrm{o}}$ & $1 \mathrm{~s}^{2} 2 \mathrm{p}^{2}{ }^{1} \mathrm{D}_{2}$ & $9.72 \mathrm{E}+10$ & $1.36 \mathrm{E}+11$ & $1.24 \mathrm{E}+11$ \\
5 & $1 \mathrm{~s} 2 \mathrm{~s}^{2} 2 \mathrm{p}^{2}{ }^{2} \mathrm{P}_{1 / 2}$ & $1 \mathrm{~s}^{2} 2 \mathrm{p}^{3}{ }^{2} \mathrm{P}_{1 / 2}^{\mathrm{o}}$ & $1.17 \mathrm{E}+10$ & $1.80 \mathrm{E}+10$ & $1.78 \mathrm{E}+10$ \\
5 & $1 \mathrm{~s} 2 \mathrm{~s}^{2} 2 \mathrm{p}^{2}{ }^{2} \mathrm{P}_{3 / 2}$ & $1 \mathrm{~s}^{2} 2 \mathrm{p}^{3}{ }^{2} \mathrm{P}_{3 / 2}^{\mathrm{o}}$ & $1.54 \mathrm{E}+10$ & $2.36 \mathrm{E}+10$ & $2.32 \mathrm{E}+10$ \\
\hline
\end{tabular}

$A$-coefficients by Chen et al. (1997) for C-like nitrogen. We find that for $\log A \geqslant 10$ present $A$-coefficients are accurate to within $20 \%$ for transitions not affected by cancellation.

\section{RADIATIVE WIDTHS}

A comparison of AS1 and AS2 radiative widths for the Kvacancy levels indicates that CRE are mainly noticeable in the highly ionized species, namely those with $N \leqslant 4$, where on average the radiative widths are increased by around $10 \%$. On the other hand, the inclusion of levels from the $n=3$ complex in the CI expansion (AS3) leads to slightly reduced radiative widths (less than 7\%) with respect to AS1 for the lowly ionized members $(N \geqslant 5)$. Larger reductions $(\sim 20 \%)$ are also observed for the lowly ionized species between HF2 (which contains CI from the $n=3$ complex) and HF1 (which contains CI only from the $n=2$ complex).

A remarkable exception is the radiative width of the $1 \mathrm{~s} 2 \mathrm{~s}^{2} 2 \mathrm{p}^{3}{ }^{5} \mathrm{~S}_{2}^{\mathrm{o}}$ level in the C-like ion. For this level, AS2 gives $A_{j}=\sum_{i} A_{j i}=7.09 \times 10^{6} \mathrm{~s}^{-1}$, which is in good agreement with HF1 $\left(7.65 \times 10^{6} \mathrm{~s}^{-1}\right)$; however, the AS3 and HF2 
Table 6

Radiative Decay Routes of $1 \mathrm{~s} 2 \mathrm{~s}^{2} 2 \mathrm{p}^{3}{ }^{5} \mathrm{~S}_{2}^{\mathrm{o}}$ in N II

\begin{tabular}{cccc}
\hline \hline$j$ & \multicolumn{1}{c}{$i$} & \multicolumn{2}{c}{$A_{j i}\left(\mathrm{~s}^{-1}\right)$} \\
\cline { 3 - 4 } & & $\mathrm{AS} 3$ & $\mathrm{HF} 2$ \\
\hline $1 \mathrm{~s} 2 \mathrm{~s}^{2} 2 \mathrm{p}^{3}{ }^{5} \mathrm{~S}_{2}^{\mathrm{o}}$ & $1 \mathrm{~s}^{2} 2 \mathrm{~s}^{2} 2 \mathrm{p}^{2}{ }^{3} \mathrm{P}_{1}$ & $2.04 \mathrm{E}+6$ & $8.57 \mathrm{E}+6$ \\
& $1 \mathrm{~s}^{2} 2 \mathrm{~s}^{2} 2 \mathrm{p}^{2}{ }^{3} \mathrm{P}_{2}$ & $2.97 \mathrm{E}+6$ & $2.53 \mathrm{E}+7$ \\
& $1 \mathrm{~s}^{2} 2 \mathrm{~s}^{2} \mathrm{p}^{2} 3 \mathrm{~d}^{5} \mathrm{P}_{1}$ & $5.07 \mathrm{E}+7$ & $3.43 \mathrm{E}+8$ \\
& $1 \mathrm{~s}^{2} 2 \mathrm{~s}^{2} \mathrm{p}^{2} 3 \mathrm{~d}^{5} \mathrm{P}_{2}$ & $8.36 \mathrm{E}+7$ & $5.70 \mathrm{E}+8$ \\
& $1 \mathrm{~s}^{2} 2 \mathrm{~s} 2 \mathrm{p}^{2} 3 \mathrm{~d}^{5} \mathrm{P}_{3}$ & $1.17 \mathrm{E}+8$ & $7.97 \mathrm{E}+8$ \\
& $1 \mathrm{~s}^{2} 2 \mathrm{p}^{3} 3 \mathrm{p}{ }^{5} \mathrm{P}_{1}$ & $7.85 \mathrm{E}+7$ & $6.99 \mathrm{E}+8$ \\
& $1 \mathrm{~s}^{2} 2 \mathrm{p}^{3} 3 \mathrm{p}^{5} \mathrm{P}_{2}$ & $1.31 \mathrm{E}+7$ & $1.16 \mathrm{E}+9$ \\
& $1 \mathrm{~s}^{2} 2 \mathrm{p}^{3} 3 \mathrm{p}{ }^{5} \mathrm{P}_{3}$ & $1.83 \mathrm{E}+8$ & $1.63 \mathrm{E}+8$ \\
\hline$\sum_{i} A_{j i}$ & $5.31 \mathrm{E}+8$ & $3.77 \mathrm{E}+9$ \\
\hline
\end{tabular}

radiative widths are respectively $A_{j}=5.31 \times 10^{8} \mathrm{~s}^{-1}$ and $A_{j}=3.77 \times 10^{9} \mathrm{~s}^{-1}$, i.e., around two orders of magnitude larger. The reason for this huge increase when levels from $n=3$ complex are included in the CI expansion may be appreciated in Table 6. Within the $n=2$ complex, the $1 \mathrm{~s}^{2} \mathrm{~s}^{2} 2 \mathrm{p}^{3}{ }^{5} \mathrm{~S}_{2}^{\mathrm{o}}$ decays radiatively to the $1 \mathrm{~s}^{2} 2 \mathrm{~s}^{2} 2 \mathrm{p}^{2}{ }^{3} \mathrm{P}_{\mathrm{j}}$ ground levels via two spin-forbidden $\mathrm{K} \alpha$ transitions which have small $A$-coefficients $\left(\lesssim 10^{7} \mathrm{~s}^{-1}\right)$. When the $n=3$ complex is taken into account, $3 \rightarrow 2$ spin-allowed channels appear which exhibit considerably larger $A$-coefficients that add up to the quoted enhancement. The observed discrepancy between AS3 and HF2 (a factor of 7) are due to severe cancellation in the $\Delta n \neq 0$ transitions.

Radiative widths computed for ions with electron number $3 \leqslant N \leqslant 6$ with the MCDF method (Chen 1986; Chen \& Crasemann 1987, 1988; Chen et al. 1997) agree with HF2 to around $20 \%$ except for the C-like species where MCDF is a factor of 4.6 higher.

\section{AUGER WIDTHS}

Auger widths computed with AS2 and HF1 agree to within $20 \%$ but are sensitive to both CRE and CI as depicted in Figures 6-7. A comparison of AS1 and AS2 shows that, on average, CRE increase Auger widths with $\log A_{\mathrm{a}} \geqslant 12$ linearly as a function of the ion electron number $N$. In AUTOSTRUCTURE CI also increases Auger widths, particularly for highly ionized species (around $28 \%$ for ions with $3 \leqslant N \leqslant 4$ ) while in HFR Auger widths are decreased (up to $15 \%$ for the lowly ionized members). We believe these contrasting outcomes are due to the way orbitals have been optimized in AUTOSTRUCTURE.

Excluding the C-like ion, MCDF Auger widths by Chen (1986), Chen \& Crasemann (1987), Chen \& Crasemann (1988), and Chen et al. (1997) with $\log A_{\mathrm{a}} \geqslant 12$ in general agree with HF2 to around 20\%. Larger discrepancies, which are mainly caused by level admixture, are encountered for a handful of $\mathrm{K}$-vacancy levels listed in Table 7. It may be seen therein that Auger widths computed with our different approximations also display a wide scatter thus supporting this diagnostic. For the $\mathrm{C}$-like ion, the MCDF Auger widths are, on average, a factor of 3 higher than HF2 and thus believed to be of poor quality.

In Table 8, Auger widths for the 1s2s2p levels of $\mathrm{Nv}$ computed with the Breit-Pauli saddle-point complex-rotation method (Davis \& Chung 1989) are compared with AS2, HF2, and the MCDF values of Chen (1986). The agreement with AS2 is within $15 \%$ while very large differences are found for the $\mathrm{HF} 2{ }^{4} \mathrm{P}_{\mathrm{j}}^{\mathrm{o}}$ levels which are most surely due to the neglect of the two-body Breit interaction in HFR. The accord with MCDF is

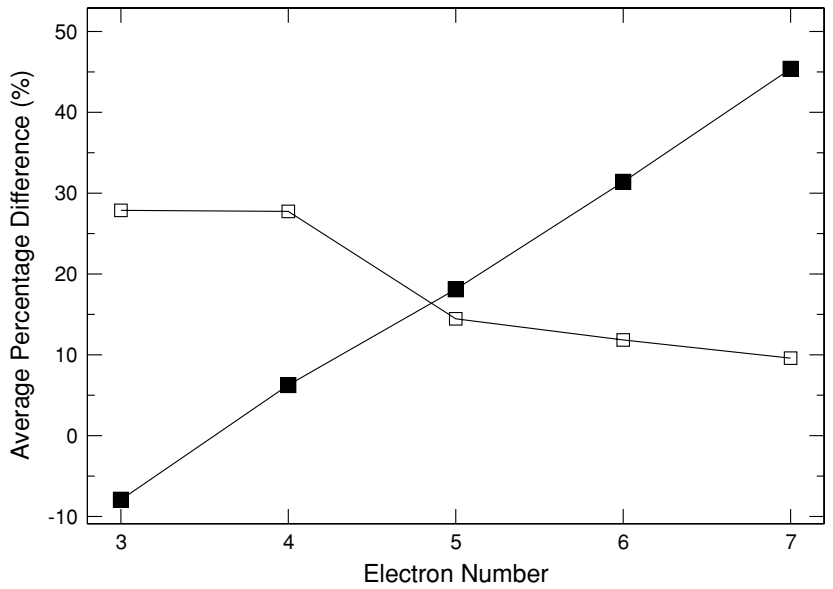

Figure 6. Average percentage difference between Auger widths $\left(\log A_{\mathrm{a}} \geqslant 12\right)$ computed with the AS2 and AS1 approximations (filled squares) and with AS3 and AS1 (open squares).

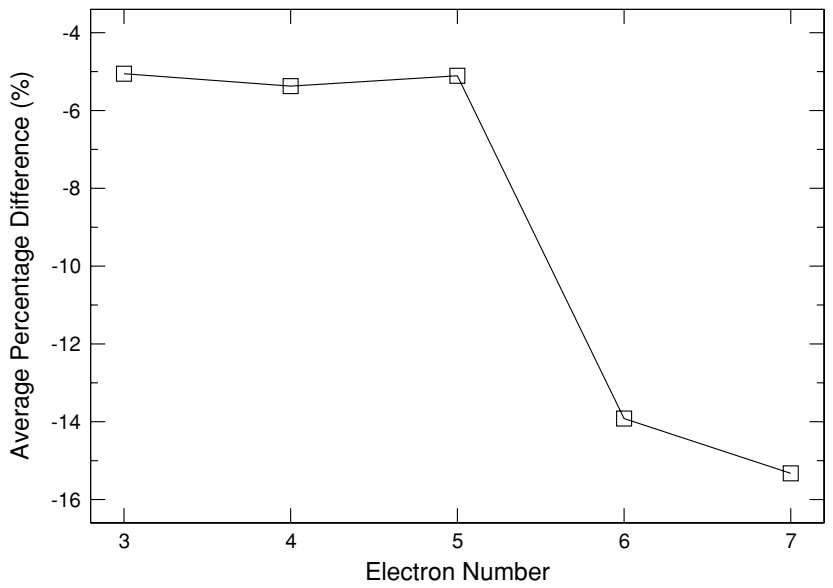

Figure 7. Average percentage difference between Auger widths $\left(\log A_{\mathrm{a}} \geqslant 12\right)$ computed with the HF2 and HF1.

around $25 \%$ except for the $1 \mathrm{~s} 2 \mathrm{~s} 2 \mathrm{p}^{2} \mathrm{P}^{\mathrm{o}}$ term where a discrepancy of a factor of 2 is encountered. The latter is difficult to explain.

Auger widths for K-vacancy terms in N IV computed with the Breit-Pauli saddle-point complex-rotation method (Lin et al. 2001, 2002; Zhang et al. 2005) are compared with AS2, HF2, and MCDF (Chen \& Crasemann 1987) in Table 9. The level of agreement with AS2 and HF2 is around 20\% except for the values quoted by Zhang et al. (2005) for the $1 \mathrm{~s} 2 \mathrm{p}^{3}{ }^{3} \mathrm{P}^{\mathrm{o}}$ and ${ }^{3} \mathrm{D}^{\mathrm{o}}$ terms, which are discrepant by about $50 \%$, in contrast with the MCDF Auger widths for these two terms which agree with AS2 and HF2 to within $10 \%$. The rest of the MCDF Auger widths are in good agreement except for the $1 \mathrm{~s} 2 \mathrm{~s} 2 \mathrm{p}^{2}{ }^{3} \mathrm{P}$ term, which has already been singled out in Table 7 as being sensitive to level mixing.

\section{PHOTOABSORPTION CROSS SECTIONS}

In Figure 8, we show the high-energy photoabsorption cross sections of $\mathrm{NI}-\mathrm{N}$ v computed with the BPRM package. Intermediate coupling has been used by implementing the AS1 approximation to describe the target wave functions. In order to resolve accurately the K-threshold region, radiative and Auger dampings are taken into account as described by Gorczyca \& McLaughlin (2000) using the Auger widths calculated with the HF2 approximation. For comparison, we have included the photoionization cross sections obtained with HULLAC 
Table 7

Discrepant Auger Rates $\left(\mathrm{s}^{-1}\right)$

\begin{tabular}{|c|c|c|c|c|c|c|c|}
\hline$N$ & Level & AS1 & AS2 & AS3 & HF1 & HF2 & $\mathrm{MCDF}^{\mathrm{a}}$ \\
\hline 3 & $1 \mathrm{~s}\left({ }^{2} \mathrm{~S}\right) 2 \mathrm{~s} 2 \mathrm{p}\left({ }^{3} \mathrm{P}^{\mathrm{o}}\right){ }^{2} \mathrm{P}_{1 / 2}^{\mathrm{o}}$ & $1.51 \mathrm{E}+13$ & $5.81 \mathrm{E}+12$ & $2.15 \mathrm{E}+13$ & $8.61 \mathrm{E}+12$ & $7.63 \mathrm{E}+12$ & $1.41 \mathrm{E}+13$ \\
\hline 3 & $1 \mathrm{~s}\left({ }^{2} \mathrm{~S}\right) 2 \mathrm{~s} 2 \mathrm{p}\left({ }^{3} \mathrm{P}^{\mathrm{o}}\right){ }^{2} \mathrm{P}_{3 / 2}^{\mathrm{o}}$ & $1.43 E+13$ & $5.27 \mathrm{E}+12$ & $2.02 \mathrm{E}+13$ & $8.29 \mathrm{E}+12$ & $7.30 \mathrm{E}+12$ & $1.35 \mathrm{E}+13$ \\
\hline 4 & $1 \mathrm{~s}\left({ }^{2} \mathrm{~S}\right) 2 \mathrm{~s} 2 \mathrm{p}^{2}\left({ }^{4} \mathrm{P}\right){ }^{3} \mathrm{P}_{0}$ & $3.09 \mathrm{E}+13$ & $1.99 \mathrm{E}+13$ & $4.41 \mathrm{E}+13$ & $1.86 \mathrm{E}+13$ & $1.77 \mathrm{E}+13$ & $3.73 E+13$ \\
\hline 4 & $1 \mathrm{~s}\left({ }^{2} \mathrm{~S}\right) 2 \mathrm{~s} 2 \mathrm{p}^{2}\left({ }^{4} \mathrm{P}\right){ }^{3} \mathrm{P}_{1}$ & $3.08 \mathrm{E}+13$ & $1.98 \mathrm{E}+13$ & $4.40 \mathrm{E}+13$ & $1.86 \mathrm{E}+13$ & $1.76 \mathrm{E}+13$ & $3.68 \mathrm{E}+13$ \\
\hline 4 & $1 \mathrm{~s}\left({ }^{2} \mathrm{~S}\right) 2 \mathrm{~s} 2 \mathrm{p}^{2}\left({ }^{4} \mathrm{P}\right){ }^{3} \mathrm{P}_{2}$ & $3.04 \mathrm{E}+13$ & $1.95 \mathrm{E}+13$ & $4.36 \mathrm{E}+13$ & $1.85 \mathrm{E}+13$ & $1.75 \mathrm{E}+13$ & $3.55 \mathrm{E}+13$ \\
\hline 4 & $1 \mathrm{~s}\left({ }^{2} \mathrm{~S}\right) 2 \mathrm{~s} 2 \mathrm{p}^{2}\left({ }^{2} \mathrm{P}\right){ }^{1} \mathrm{P}_{1}$ & $2.26 \mathrm{E}+13$ & $2.88 \mathrm{E}+13$ & $2.62 E+13$ & $2.46 \mathrm{E}+13$ & $2.34 \mathrm{E}+13$ & $1.43 E+14$ \\
\hline 4 & $1 \mathrm{~s}\left({ }^{2} \mathrm{~S}\right) 2 \mathrm{~s} 2 \mathrm{p}^{2}\left({ }^{2} \mathrm{~S}\right){ }^{1} \mathrm{~S}_{0}$ & $1.34 \mathrm{E}+14$ & $1.33 \mathrm{E}+14$ & $1.77 \mathrm{E}+14$ & $1.28 \mathrm{E}+14$ & $1.19 \mathrm{E}+14$ & $1.77 \mathrm{E}+13$ \\
\hline 5 & $1 \mathrm{~s}\left({ }^{2} S\right) 2 \mathrm{~s} 2 \mathrm{p}^{3}\left({ }^{5} \mathrm{~S}^{\mathrm{o}}\right){ }^{4} \mathrm{~S}_{3 / 2}^{\mathrm{o}}$ & $3.90 \mathrm{E}+13$ & $2.98 \mathrm{E}+13$ & $4.10 \mathrm{E}+13$ & $2.54 \mathrm{E}+13$ & $2.48 \mathrm{E}+13$ & $3.89 \mathrm{E}+13$ \\
\hline 5 & $1 \mathrm{~s}\left({ }^{2} S\right) 2 \mathrm{~s} 2 \mathrm{p}^{3}\left({ }^{3} \mathrm{~S}^{\mathrm{o}}\right){ }^{2} \mathrm{~S}_{1 / 2}^{\mathrm{o}}$ & $2.34 \mathrm{E}+13$ & $3.09 \mathrm{E}+13$ & $2.88 \mathrm{E}+13$ & $5.30 \mathrm{E}+13$ & $1.31 \mathrm{E}+14$ & $3.49 \mathrm{E}+13$ \\
\hline 5 & $1 \mathrm{~s}\left({ }^{2} \mathrm{~S}\right) 2 \mathrm{~s} 2 \mathrm{p}^{3}\left({ }^{1} \mathrm{P}^{\mathrm{o}}\right){ }^{2} \mathrm{P}_{1 / 2}^{\mathrm{o}}$ & $1.37 \mathrm{E}+14$ & $1.67 \mathrm{E}+14$ & $1.56 \mathrm{E}+14$ & $1.27 \mathrm{E}+14$ & $3.48 \mathrm{E}+13$ & $1.52 \mathrm{E}+14$ \\
\hline
\end{tabular}

Note.

${ }^{a}$ MCDF computations by Chen (1986), Chen \& Crasemann (1987), and Chen \& Crasemann (1988).

Table 8

Auger Energy Widths (au) for 1s2s2p Levels in N v

\begin{tabular}{cccc}
\hline \hline Level & AS2 & HF2 & Other Theory \\
\hline $1 \mathrm{~s}\left({ }^{2} \mathrm{~S}\right) 2 \mathrm{~s} 2 \mathrm{p}\left({ }^{3} \mathrm{P}^{\mathrm{o}}\right){ }^{4} \mathrm{P}_{1 / 2}^{\mathrm{o}}$ & $1.46 \mathrm{E}-08$ & $3.48 \mathrm{E}-10$ & $1.50 \mathrm{E}-08^{\mathrm{a}}, 1.532 \mathrm{E}-08^{\mathrm{b}}$ \\
$1 \mathrm{~s}\left({ }^{2} \mathrm{~S}\right) 2 \mathrm{~s} 2 \mathrm{p}\left({ }^{3} \mathrm{P}^{\mathrm{o}}\right){ }^{4} \mathrm{P}_{3 / 2}^{\mathrm{o}}$ & $4.53 \mathrm{E}-09$ & $8.83 \mathrm{E}-10$ & $4.98 \mathrm{E}-09^{\mathrm{a}}, 3.952 \mathrm{E}-09^{\mathrm{b}}$ \\
$1 \mathrm{~s}\left({ }^{2} \mathrm{~S}\right) 2 \mathrm{~s} 2 \mathrm{p}\left({ }^{3} \mathrm{P}^{\mathrm{o}}\right){ }^{4} \mathrm{P}_{5 / 2}^{\mathrm{o}}$ & $4.26 \mathrm{E}-10$ & & $4.587 \mathrm{E}-10^{\mathrm{b}}$ \\
$1 \mathrm{~s}\left({ }^{2} \mathrm{~S}\right) 2 \mathrm{~s} 2 \mathrm{p}\left({ }^{3} \mathrm{P}^{\mathrm{o}}\right){ }^{2} \mathrm{P}^{\mathrm{o}}$ & $1.32 \mathrm{E}-04$ & $1.79 \mathrm{E}-04$ & $3.31 \mathrm{E}-04^{\mathrm{a}}, 1.54 \mathrm{E}-04^{\mathrm{b}}$ \\
$1 \mathrm{~s}\left({ }^{2} \mathrm{~S}\right) 2 \mathrm{~s} 2 \mathrm{p}\left({ }^{1} \mathrm{P}^{\mathrm{o}}\right){ }^{2} \mathrm{P}^{\mathrm{o}}$ & $1.68 \mathrm{E}-03$ & $1.47 \mathrm{E}-03$ & $1.14 \mathrm{E}-03^{\mathrm{a}}, 1.53 \mathrm{E}-03^{\mathrm{b}}$ \\
\hline
\end{tabular}

Notes.

${ }^{a}$ MCDF calculations by Chen (1986).

b Breit-Pauli saddle-point complex-rotation method (Davis \& Chung 1989).

and those by Reilman \& Manson (1979), the latter calculated in a central-field potential. This comparison shows that the K-threshold energies of BPRM and HULLAC are in very good accord (within $1 \mathrm{eV}$ ) and the background cross sections to within $\sim 10 \%$. Note that for the sake of comparison, we have used HULLAC only to compute the direct bound-free photoionization cross section and not the resonances. Background cross sections by Reilman \& Manson (1979) are in excellent agreement with BPRM for all ions, but K-edge positions and structures are clearly discrepant. The present BPRM calculations result in smeared $\mathrm{K}$ edges due to the dominance of the Auger spectator (KLL) channels over the participator (KLn) channels. This overall behavior is similar to that reported in previous calculations (Kallman et al. 2004; Witthoeft et al. 2009), and in particular to that displayed by the corresponding oxygen ions (see Figure 5 in García et al. 2005).

\section{MACHINE-READABLE TABLES}

We include two machine-readable tables. For nitrogen ions with electron occupancy $N=1-7$ and for both valence and Auger levels, Table 10 tabulates the spin multiplicity, total orbital angular momentum, and total angular momentum quantum numbers, configuration assignment, energy, and radiative and Auger widths. Fields not applicable or not computed are labeled with the identifier " $-9.99 \mathrm{E}+2$. ." For K transitions, Table 11 tabulates the wavelength, $A$-coefficient, and $g f$-value. The printed stub versions list the corresponding data only for the Li-like ion $(N=3)$. The photoionization curves may be requested from the corresponding author.

\section{DISCUSSION AND CONCLUSIONS}

Detailed calculations have been carried out on the atomic properties of K-vacancy states in ions of the nitrogen isonu-
Table 9

Auger Widths (meV) for $K$-Vacancy Terms in N IV

\begin{tabular}{llll}
\hline \multicolumn{1}{c}{ Term } & AS2 & HF2 & Other Theory \\
\hline $1 \mathrm{~s} 2 \mathrm{~s}^{2} 2 \mathrm{p}^{3} \mathrm{P}^{\mathrm{o}}$ & 84.1 & 71.8 & $77.4^{\mathrm{a}}, 79.0^{\mathrm{b}}$ \\
$1 \mathrm{~s}\left({ }^{2} \mathrm{~S}\right) 2 \mathrm{~s} 2 \mathrm{p}^{2}\left({ }^{4} \mathrm{P}\right){ }^{3} \mathrm{P}$ & 12.9 & 11.6 & $23.8^{\mathrm{a}}, 10.8^{\mathrm{b}}$ \\
$1 \mathrm{~s}\left({ }^{2} \mathrm{~S}\right) 2 \mathrm{~s} 2 \mathrm{p}^{2}\left({ }^{2} \mathrm{D}\right){ }^{3} \mathrm{D}$ & 66.9 & 62.6 & $53.4^{\mathrm{a}}, 57.7^{\mathrm{b}}$ \\
$1 \mathrm{~s}\left({ }^{2} \mathrm{~S}\right) 2 \mathrm{~s} 2 \mathrm{p}^{2}\left({ }^{2} \mathrm{~S}\right){ }^{3} \mathrm{~S}$ & 31.2 & 29.7 & $26.7^{\mathrm{a}}, 28.6^{\mathrm{b}}$ \\
$1 \mathrm{~s}\left({ }^{2} \mathrm{~S}\right) 2 \mathrm{~s} 2 \mathrm{p}^{2}\left({ }^{2} \mathrm{P}\right){ }^{3} \mathrm{P}$ & 66.4 & 55.5 & $58.5^{\mathrm{a}}, 55.0^{\mathrm{b}}$ \\
$1 \mathrm{~s} 2 \mathrm{~s}^{2} 2 \mathrm{p}{ }^{1} \mathrm{P}^{\mathrm{o}}$ & 55.2 & 48.3 & $53.8^{\mathrm{a}}, 58^{\mathrm{c}}$ \\
$1 \mathrm{~s} 2 \mathrm{p}^{3}{ }^{1} \mathrm{P}^{\mathrm{o}}$ & 44.9 & 47.0 & $43.8^{\mathrm{a}}, 43^{\mathrm{c}}$ \\
$1 \mathrm{~s} 2 \mathrm{p}^{3}{ }^{3} \mathrm{D}^{\mathrm{o}}$ & 80.7 & 80.3 & $75.0^{\mathrm{a}}, 53.87^{\mathrm{d}}$ \\
$1 \mathrm{~s} 2 \mathrm{p}^{3}{ }^{3} \mathrm{P}^{\mathrm{o}}$ & 47.4 & 47.5 & $45.5^{\mathrm{a}}, 34.16^{\mathrm{d}}$ \\
\hline
\end{tabular}

Notes.

${ }^{a}$ MCDF method (Chen \& Crasemann 1987).

${ }^{b}$ Breit-Pauli saddle-point complex-rotation method (Lin et al. 2001).

${ }^{c}$ Breit-Pauli saddle-point complex-rotation method (Lin et al. 2002).

${ }^{d}$ Breit-Pauli saddle-point complex-rotation method (Zhang et al. 2005).

clear sequence. Data sets containing energy levels, wavelengths, $A$-coefficients, and radiative and Auger widths for K-vacancy levels have been computed with the atomic structure codes HFR and AUTOSTRUCTURE. High-energy photoionization and photoabsorption cross sections for members with electron occupancies $N \geqslant 3$ have been calculated with the BPRM and HULLAC codes.

Our best approximation (HF2) takes into account both CRE and configuration interaction from the $n=3$ complex. By comparing results from different approximations with previous theoretical work and the few spectroscopic measurements available, we conclude that level energies and wavelengths for all the nitrogen ions considered in the present calculations can be quoted to be accurate to within $0.5 \mathrm{eV}$ and $100 \mathrm{~m} \AA$, respectively. The accuracy of $A$-coefficients and radiative and Auger widths is estimated at approximately $20 \%$ for transitions affected by neither cancellation nor strong level admixture. Outstanding discrepancies are found with some MCDF data, in particular wavelengths and $A$-coefficients for the $\mathrm{C}$-like ion, which are believed to be due to numerical error by Chen et al. (1997).

We have also presented detailed photoabsorption cross sections of nitrogen ions in the near K-threshold region. Due to the lack of previous experimental and theoretical results, we have also performed simpler calculations using HULLAC in order to check for consistency and to estimate accuracy. Comparison of BPRM and HULLAC indicates that present K-threshold energies are accurate to within $1 \mathrm{eV}$. However, background cross sections are in better agreement with those computed by 


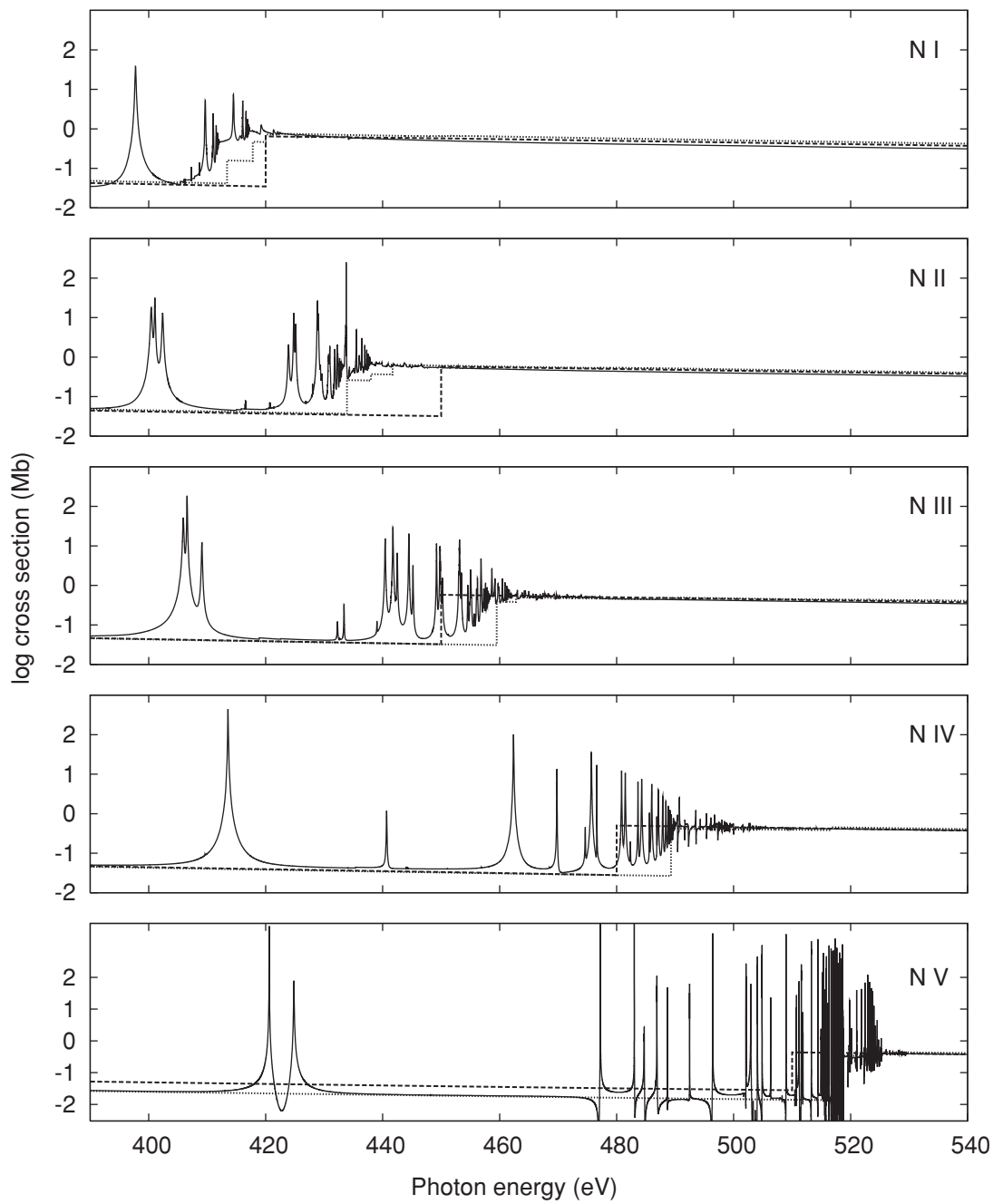

Figure 8. High-energy photoabsorption cross sections for nitrogen ions in the K-edge region. Solid curve: BPRM. Dotted curve: HULLAC. Dashed curve: Reilman \& Manson (1979).

Table 10

Valence and Auger Levels for Nitrogen Ions

\begin{tabular}{lcccccccc}
\hline \hline$N$ & $i$ & $2 S+1$ & $L$ & $2 J$ & Configuration & $\begin{array}{c}\text { Energy } \\
(\mathrm{eV})\end{array}$ & $\begin{array}{c}A \mathrm{Ar} \\
\left(\mathrm{s}^{-1}\right)\end{array}$ & $\begin{array}{c}A \mathrm{a} \\
\left(\mathrm{s}^{-1}\right)\end{array}$ \\
\hline 3 & 1 & 2 & 0 & 1 & $1 \mathrm{~s} 22 \mathrm{~s} 2 \mathrm{~S} 1 / 2$ & 0.0000 & $-9.99 \mathrm{E}+02$ & $-9.99 \mathrm{E}+02$ \\
3 & 2 & 2 & 1 & 1 & $1 \mathrm{~s} 22 \mathrm{p} 2 \mathrm{Po} 1 / 2$ & 9.9459 & $3.32 \mathrm{E}+08$ & $-9.99 \mathrm{E}+02$ \\
3 & 3 & 2 & 1 & 3 & $1 \mathrm{~s} 22 \mathrm{p} 2 \mathrm{Po} 3 / 2$ & 9.9774 & $3.35 \mathrm{E}+08$ & $-9.99 \mathrm{E}+02$ \\
3 & 4 & 2 & 0 & 1 & $1 \mathrm{~s} 2 \mathrm{~s} 22 \mathrm{~S} 1 / 2$ & 410.1562 & $1.22 \mathrm{E}+11$ & $9.79 \mathrm{E}+13$ \\
3 & 5 & 4 & 1 & 1 & $1 \mathrm{~s}(2 \mathrm{~S}) 2 \mathrm{~s} 2 \mathrm{p}(3 \mathrm{Po}) 4 \mathrm{Po} 1 / 2$ & 413.0288 & $5.05 \mathrm{E}+06$ & $1.44 \mathrm{E}+07$ \\
3 & 6 & 4 & 1 & 3 & $1 \mathrm{~s}(2 \mathrm{~S}) 2 \mathrm{~s} 2 \mathrm{p}(3 \mathrm{Po}) 4 \mathrm{Po} 3 / 2$ & 413.0471 & $1.27 \mathrm{E}+07$ & $3.65 \mathrm{E}+07$ \\
3 & 7 & 4 & 1 & 5 & $1 \mathrm{~s}(2 \mathrm{~S}) 2 \mathrm{~s} 2 \mathrm{p}(3 \mathrm{Po}) 4 \mathrm{P} 05 / 2$ & 413.0778 & $0.00 \mathrm{E}+00$ & $1.76 \mathrm{E}+07$ \\
3 & 8 & 2 & 1 & 1 & $1 \mathrm{~s}(2 \mathrm{~S}) 2 \mathrm{~s} 2 \mathrm{p}(3 \mathrm{PO}) 2 \mathrm{Po} 1 / 2$ & 420.8755 & $1.65 \mathrm{E}+12$ & $7.63 \mathrm{E}+12$ \\
3 & 9 & 2 & 1 & 3 & $1 \mathrm{~s}(2 \mathrm{~S}) 2 \mathrm{~s} 2 \mathrm{p}(3 \mathrm{Po}) 2 \mathrm{Po} 3 / 2$ & 420.8968 & $1.65 \mathrm{E}+12$ & $7.30 \mathrm{E}+12$ \\
3 & 10 & 4 & 1 & 1 & $1 \mathrm{~s}(2 \mathrm{~S}) 2 \mathrm{p} 2(3 \mathrm{P}) 4 \mathrm{P} 1 / 2$ & 424.3267 & $7.99 \mathrm{E}+08$ & $5.54 \mathrm{E}+06$ \\
3 & 11 & 4 & 1 & 3 & $1 \mathrm{~s}(2 \mathrm{~S}) 2 \mathrm{p} 2(3 \mathrm{P}) 4 \mathrm{P} 3 / 2$ & 424.3446 & $8.06 \mathrm{E}+08$ & $4.65 \mathrm{E}+08$ \\
3 & 12 & 4 & 1 & 5 & $1 \mathrm{~s}(2 \mathrm{~S}) 2 \mathrm{p} 2(3 \mathrm{P}) 4 \mathrm{P} 5 / 2$ & 424.3741 & $8.15 \mathrm{E}+08$ & $2.85 \mathrm{E}+09$ \\
3 & 13 & 2 & 1 & 1 & $1 \mathrm{~s}(2 \mathrm{~S}) 2 \mathrm{~s} 2 \mathrm{p}(1 \mathrm{Po}) 2 \mathrm{Po} 1 / 2$ & 425.6391 & $1.63 \mathrm{E}+11$ & $6.06 \mathrm{E}+13$ \\
3 & 14 & 2 & 1 & 3 & $1 \mathrm{~s}(2 \mathrm{~S}) 2 \mathrm{~s} 2 \mathrm{p}(1 \mathrm{Po}) 2 \mathrm{Po} 3 / 2$ & 425.6545 & $1.55 \mathrm{E}+11$ & $6.10 \mathrm{E}+13$ \\
3 & 15 & 2 & 2 & 3 & $1 \mathrm{~s}(2 \mathrm{~S}) 2 \mathrm{p} 2(1 \mathrm{D}) 2 \mathrm{D} 3 / 2$ & 429.2436 & $8.33 \mathrm{E}+11$ & $1.07 \mathrm{E}+14$ \\
3 & 16 & 2 & 2 & 5 & $1 \mathrm{~s}(2 \mathrm{~S}) 2 \mathrm{p} 2(1 \mathrm{D}) 2 \mathrm{D} 5 / 2$ & 429.2442 & $8.32 \mathrm{E}+11$ & $1.07 \mathrm{E}+14$ \\
3 & 17 & 2 & 1 & 1 & $1 \mathrm{~s}(2 \mathrm{~S}) 2 \mathrm{p} 2(3 \mathrm{P}) 2 \mathrm{P} 1 / 2$ & 430.3236 & $2.68 \mathrm{E}+12$ & $1.20 \mathrm{E}+08$ \\
3 & 18 & 2 & 1 & 3 & $1 \mathrm{~s}(2 \mathrm{~S}) 2 \mathrm{p} 2(3 \mathrm{P}) 2 \mathrm{P} 3 / 2$ & 430.3597 & $2.68 \mathrm{E}+12$ & $4.50 \mathrm{E}+10$ \\
3 & 19 & 2 & 0 & 1 & $1 \mathrm{~s}(2 \mathrm{~S}) 2 \mathrm{p} 2(1 \mathrm{~S}) 2 \mathrm{~S} 1 / 2$ & 437.1874 & $7.86 \mathrm{E}+11$ & $1.60 \mathrm{E}+13$ \\
\hline
\end{tabular}

(This table is available in its entirety in a machine-readable form in the online journal. A portion is shown here for guidance regarding its form and content.) 
Table 11

Radiative K-Transition Data for Nitrogen Ions

\begin{tabular}{lccccc}
\hline \hline$N$ & $j$ & $i$ & $\begin{array}{c}\text { Wavelength } \\
(0.1 \mathrm{~nm})\end{array}$ & $\begin{array}{c}A \text {-coefficient } \\
\left(\mathrm{s}^{-1}\right)\end{array}$ & $g f$-value \\
\hline 3 & 4 & 2 & 30.9798 & $4.08 \mathrm{E}+10$ & $1.17 \mathrm{E}-02$ \\
3 & 4 & 3 & 30.9822 & $8.08 \mathrm{E}+10$ & $2.33 \mathrm{E}-02$ \\
3 & 5 & 1 & 30.0183 & $5.05 \mathrm{E}+06$ & $1.36 \mathrm{E}-06$ \\
3 & 6 & 1 & 30.0170 & $1.27 \mathrm{E}+07$ & $6.87 \mathrm{E}-06$ \\
3 & 8 & 1 & 29.4586 & $1.65 \mathrm{E}+12$ & $4.29 \mathrm{E}-01$ \\
3 & 9 & 1 & 29.4571 & $1.65 \mathrm{E}+12$ & $8.61 \mathrm{E}-01$ \\
3 & 10 & 2 & 29.9203 & $9.70 \mathrm{E}+06$ & $2.61 \mathrm{E}-06$ \\
3 & 10 & 3 & 29.9226 & $2.36 \mathrm{E}+05$ & $6.34 \mathrm{E}-08$ \\
3 & 11 & 2 & 29.9191 & $7.01 \mathrm{E}+04$ & $3.77 \mathrm{E}-08$ \\
3 & 11 & 3 & 29.9213 & $1.58 \mathrm{E}+07$ & $8.49 \mathrm{E}-06$ \\
3 & 12 & 3 & 29.9192 & $2.14 \mathrm{E}+07$ & $1.72 \mathrm{E}-05$ \\
3 & 13 & 1 & 29.1289 & $1.62 \mathrm{E}+11$ & $4.12 \mathrm{E}-02$ \\
3 & 14 & 1 & 29.1279 & $1.54 \mathrm{E}+11$ & $7.83 \mathrm{E}-02$ \\
3 & 15 & 2 & 29.5695 & $7.16 \mathrm{E}+11$ & $3.76 \mathrm{E}-01$ \\
3 & 15 & 3 & 29.5717 & $1.17 \mathrm{E}+11$ & $6.12 \mathrm{E}-02$ \\
3 & 16 & 3 & 29.5717 & $8.32 \mathrm{E}+11$ & $6.55 \mathrm{E}-01$ \\
3 & 17 & 2 & 29.4935 & $1.79 \mathrm{E}+12$ & $4.68 \mathrm{E}-01$ \\
3 & 17 & 3 & 29.4957 & $8.89 \mathrm{E}+11$ & $2.32 \mathrm{E}-01$ \\
3 & 18 & 2 & 29.4910 & $4.24 \mathrm{E}+11$ & $2.21 \mathrm{E}-01$ \\
3 & 18 & 3 & 29.4932 & $2.26 \mathrm{E}+12$ & $1.18 \mathrm{E}+00$ \\
3 & 19 & 2 & 29.0197 & $2.56 \mathrm{E}+11$ & $6.46 \mathrm{E}-02$ \\
3 & 19 & 3 & 29.0218 & $5.28 \mathrm{E}+11$ & $1.33 \mathrm{E}-01$ \\
\hline & & & & & \\
\hline
\end{tabular}

(This table is available in its entirety in a machine-readable form in the online journal. A portion is shown here for guidance regarding its form and content.)

Reilman \& Manson (1979) in a central-field potential for all ions except the Li-like system. These photoabsorption cross sections and their structures are similar to those displayed by ions in the same isoelectronic sequence (Witthoeft et al. 2009), especially to the corresponding oxygen ions (García et al. 2005).

The present atomic data sets are available on request and will be incorporated in the XSTAR modeling code in order to generate improved opacities in the nitrogen K-edge region, which will lead to useful astrophysical diagnostics such as those mentioned in Section 1.

We thank the anonymous referee for suggestions that improved the clarity of this paper. This work was funded in part by the NASA Astronomy and Physics Research and Analysis Program. P.P. and P.Q. are research associates of the Belgian FRS-FNRS. E.B. acknowledges funding from NASA grant 08-ADP08-0076. E.B. and M.K. thank Michel Busquet for his significant contributions to the revised version of HULLAC used for this work. This research has made use of NASA's Astrophysics Data System.

\section{REFERENCES}

Arav, N., et al. 2007, ApJ, 658, 829

Badnell, N. R. 1986, J. Phys. B: At. Mol. Opt. Phys., 19, 3827

Badnell, N. R. 1997, J. Phys. B: At. Mol. Opt. Phys., 30, 1

Bar-Shalom, A., Klapisch, M., \& Oreg, J. 1988, Phys. Rev. A, 38, 1773

Bar-Shalom, A., Klapisch, M., \& Oreg, J. 2001, JQRST, 71, 169

Bautista, M. A., Mendoza, C., Kallman, T. R., \& Palmeri, P. 2003, A\&A, 403, 339

Behar, E., Jacobs, V. L., Oreg, J., Bar-Shalom, A., \& Haan, S. L. 2000, Phys. Rev. A, 62, 030501

Behar, E., Jacobs, V. L., Oreg, J., Bar-Shalom, A., \& Haan, S. L. 2004, Phys. Rev. A, 69, 022704

Behar, E., \& Netzer, H. 2002, ApJ, 570, 165
Behar, E., Rasmussen, A. P., Blustin, A. J., Sako, M., Kahn, S. M., Kaastra, J. S., Branduardi-Raymont, G., \& Steenbrugge, K. C. 2003, ApJ, 598, 232

Behar, E., Sako, M., \& Kahn, S. M. 2001, ApJ, 563, 497

Beiersdorfer, P., Crespo López-Urrutia, J. R., Springer, P., Utter, S. B., \& Wong, K. L. 1999, Rev. Sci. Instrum., 70, 276

Berrington, K. A., Burke, P. G., Butler, K., Seaton, M. J., Storey, P. J., Taylor, K. T., \& Yan, Y. 1987, J. Phys. B: At. Mol. Opt. Phys., 20, 6379

Berry, H. G., Brooks, R. L., Cheng, K. T., Hardis, J. E., \& Ray, W. 1982, Phys. Scr., 25, 391

Brinkman, A. C., Kaastra, J. S., van der Meer, R. L. J., Kinkhabwala, A., Behar, E., Kahn, S. M., Paerels, F. B. S., \& Sako, M. 2002, A\&A, 396, 761

Chen, M. H. 1986, At. Data Nucl. Data Tables, 34, 301

Chen, M. H., \& Crasemann, B. 1987, At. Data Nucl. Data Tables, 37, 419

Chen, M. H., \& Crasemann, B. 1988, At. Data Nucl. Data Tables, 38, 381

Chen, M. H., Reed, K. J., McWilliams, D. M., Guo, D. S., Barlow, L., Lee, M., \& Walker, V. 1997, At. Data Nucl. Data Tables, 65, 289

Chung, K. T. 1990, Phys. Rev. A, 42, 645

Cowan, R. D. 1981, The Theory of Atomic Structure and Spectra (Berkeley, CA: Univ. California Press)

Davis, B. F., \& Chung, K. T. 1989, Phys. Rev. A, 39, 3942

Eissner, W., Jones, M., \& Nussbaumer, H. 1974, Comput. Phys. Commun., 8 , 270

Favata, F., Neiner, C., Testa, P., Hussain, G., \& Sanz-Forcada, J. 2009, A\&A, 495, 217

García, J., Mendoza, C., Bautista, M. A., Gorczyca, T. W., Kallman, T. R., \& Palmeri, P. 2005, ApJS, 158, 68

Gorczyca, T. W., \& Badnell, N. R. 1996, J. Phys. B: At. Mol. Opt. Phys., 29, L283

Gorczyca, T. W., \& McLaughlin, B. M. 2000, J. Phys. B: At. Mol. Opt. Phys., 33, L859

Hardis, J. E., Berry, H. G., Curtis, L. J., \& Livingston, A. E. 1984, Phys. Scr., 30,189

Hata, J., \& Grant, I. P. 1983, J. Phys. B: At. Mol. Opt. Phys., 16, L125

Hsu, J.-J., Chung, K. T., \& Huang, K.-N. 1991, Phys. Rev. A, 44, 5485

Kaastra, J. S., de Vries, C. P., Costantini, E., \& den Herder, J. W. A. 2009, A\&A, 497, 291

Kallman, T., \& Bautista, M. 2001, ApJS, 133, 221

Kallman, T. R., Palmeri, P., Bautista, M. A., Mendoza, C., \& Krolik, J. H. 2004, ApJS, 155, 675

Klapisch, M., \& Busquet, M. 2009, High Energy Density Phys., 5, 105

Klapisch, M., Schwob, J. L., Fraenkel, B. S., \& Oreg, J. 1977, J. Opt. Soc. Am., 67, 148

Leutenegger, M. A., Kahn, S. M., \& Ramsay, G. 2003, ApJ, 585, 1015

Lin, H., Hsue, C.-S., \& Chung, K. T. 2002, Phys. Rev. A, 65, 032706

Lin, S.-H., Hsue, C.-S., \& Chung, K. T. 2001, Phys. Rev. A, 64, 012709

Miyata, E., Masai, K., \& Hughes, J. P. 2008, PASJ, 60, 521

Ness, J.-U., et al. 2003, ApJ, 594, L127

Oreg, J., Goldstein, W. H., Klapisch, M., \& Bar-Shalom, A. 1991, Phys. Rev. A, 44, 1750

Palmeri, P., Quinet, P., Mendoza, C., Bautista, M. A., García, J., \& Kallman, T. R. 2008a, ApJS, 177, 408

Palmeri, P., Quinet, P., Mendoza, C., Bautista, M. A., García, J., Witthoeft, M. C., \& Kallman, T. R. 2008b, ApJS, 179, 542

Pradhan, A. K. 2000, ApJ, 545, L165

Ralchenko, Y., Kramida, A. E., Reader, J., \& NIST ADS Team. 2008, NIST Atomic Spectra Database, version 3.1.5 (Gaithersburg, MD: NIST), http:// physics.nist.gov/asd3

Ramírez, J. M., Komossa, S., Burwitz, V., \& Mathur, S. 2008, ApJ, 681, 965

Reilman, R. F., \& Manson, S. T. 1979, ApJS, 40, 815

Robicheaux, F., Gorczyca, T. W., Pindzola, M. S., \& Badnell, N. R. 1995, Phys. Rev. A, 52, 1319

Sako, M., et al. 2001, A\&A, 365, L168

Scott, N. S. \& Burke, P. G. 1980, J. Phys. B: At. Mol. Opt. Phys., 13, 4299

Scott, N. S., \& Taylor, K. T. 1982, Comput. Phys. Commun., 25, 347

Seaton, M. J. 1987, J. Phys. B: At. Mol. Opt. Phys., 20, 6363

Shiu, W. C., Hsue, C.-S., \& Chung, K. T. 2001, Phys. Rev. A, 64, 022714

Steenbrugge, K. C., et al. 2005, A\&A, 434, 569

Wang, F., \& Gou, B. C. 2006, At. Data Nucl. Data Tables, 92, 176

Witthoeft, M. C., Bautista, M. A., Mendoza, C., Kallman, T. R., Palmeri, P., \& Quinet, P. 2009, ApJS, 182, 127

Yang, H. Y., \& Chung, K. T. 1995, Phys. Rev. A, 51, 3621

Yao, Y., Schulz, N. S., Gu, M. F., Nowak, M. A., \& Canizares, C. R. 2009, ApJ, 696, 1418

Zhang, M., Gou, B. C., \& Cui, L. L. 2005, J. Phys. B: At. Mol. Opt. Phys., 38, 3567 